\title{
PBL Field Deployment: Lessons Learned Adding a Problem-Based Learning Unit to a Traditional Engineering Lecture and Lab Course
}

\section{Ms. MaryShannon Williams, University of Missouri, Columbia}

MaryShannon Williams graduated with a Bachelor of Science in Radio-TV-Film from the University of Texas, Austin, in 1994; and completed her Master of Arts in Education at the University of Texas at San Antonio in 2004. She spent 10 years working in K-12 education prior to becoming an Instructional Designer for The University of Texas Health Science Center's School of Nursing. In 2011, she entered the doctoral program in the School of Information Science and Learning Technology (SISLT) in the College of Education at the University of Missouri, Columbia, (USA). Shortly thereafter, she began working with an Environmental Engineering Professor to provide a formative evaluation of his course, using the ABET framework as a lens for assessment. She began researching engineering education, specifically exploring the implementation of Problem-based Learning (PBL) to help prepare students to meet the ABET standards. She is currently working as a graduate assistant for the eThemes project while completing her comprehensive examination, research proposal, and dissertation.

\section{Ms. Sara Elizabeth Ringbauer, University of Missouri - Columbia}

Sara Ringbauer is a doctoral student in the School of Information Sciences \& Learning Technologies (SISLT) at the University of Missouri - Columbia. Ms. Ringbauer's research interests include increasing STEM learning through the use of technology and effective use of handheld and wearable computers in the classroom. 


\title{
PBL Field Deployment:
}

\section{Lessons Learned Adding a Problem-Based Learning Unit to a Traditional Engineering Lecture and Lab Course}

\begin{abstract}
:
This evaluation study examines the design of a problem-based learning (PBL) air quality webbased unit and its incorporation into the lab portion of an environmental engineering course. Research questions include: R1) What themes emerge from student and instructor interviews about their PBL experience? R2) How can we use these themes to improve future PBL implementation? Participants included 7 undergraduate, Introduction to Environmental Engineering students ( 4 males, 3 females), 1 course instructor, and 2 graduate teaching assistants from a large, Midwestern university. Researchers employed a formative evaluation approach, consisting of semi-structured interviews. Researchers used grounded theory to analyze data. Themes emerged in the following three categories: student implications, instructor implications, and PBL considerations. The researchers identified several important considerations when implementing a PBL lab unit in a traditional environmental engineering lecture with lab course. Recommendations for those considering using PBL include: 1) reassure students upfront that it is normal to experience frustration or discomfort when first starting a PBL; 2) actively collaborate with instructional designers to ensure alignment between learning objectives, instruction, and assessment, 3) embed the learning in a relevant learning context, and 4) be sure to manage group size - groups of 3 are optimal for active group engagement.
\end{abstract}




\section{Introduction}

Problem-based learning (PBL), the practice of presenting students with ill-structured problems to solve at the beginning of the learning process, has proven to be an effective strategy for preparing professionals to meet the demands of the $21^{\text {st }}$ century workplace. When implemented well, problem-based learning mirrors both the technical skills and the soft skills required in environmental engineering jobs. These soft skills such as teamwork, argumentation, communication, listening, time management and meeting deadlines are often overlooked in traditional engineering lecture courses ${ }^{1}$. Incorporating a PBL unit into an environmental engineering lecture course provides an opportunity for students to improve these soft skills.

PBL has become the norm in effective medical school curriculum design ${ }^{2,3,4}$. PBL prepares students to solve the complex, ill-structured type of problems prevalent in the daily life of working engineers ${ }^{5}$. While PBL has been shown to improve learning that is problem-focused, student-centered, self-directed and self-reflective ${ }^{6}$, few studies discuss the difficulties faced when instructors attempt to implement this strategy in the curriculum.

Educators may find themselves asking why implementing PBL in engineering courses is so difficult. Bouhuijs ${ }^{2}$ points to two key reasons for this difficulty. First, there is a shift in culture, requiring a more active learning approach versus the more traditional lecture-based model popular in engineering education.

It is naïve to think that PBL can be introduced without touching the curriculum. Usually the changes needed are big, and so one can expect teachers to worry about how their courses will look like in the new curriculum. Curricular changes always introduce these tensions, but in the case of PBL, the uncertainty is more intense (p.20) ${ }^{2}$.

Second, implementing PBL requires a shift in organization and management. With the instructor taking on the role of facilitator in PBL environments, more time is spent upfront preparing for and redesigning learning materials. Course time is more student-centered, with collaboration and teamwork the focus of the learning. Making this transition for the seasoned lecturer is often uncomfortable and takes some adjustment.

A better understanding of the specific challenges instructors face when implementing a PBL environment is needed. This evaluation study examines the design of a problem-based learning (PBL) air quality web-based unit and its incorporation in to the lab portion of an environmental engineering course. This evaluation explores both student and instructor perceptions related to the PBL implementation. The goal of this evaluation is to address the gap in literature related to the implementation of PBL in engineering education. Additionally, it will help engineering educators avoid pitfalls that may detract from the benefits inherent in the effective use of PBL and will further address ways to effectively address Accreditation Board for Engineering and Technology (ABET) professional skills ${ }^{7,8}$. 


\section{Review of Literature}

\section{What is PBL?}

Jonassen $^{6}$, in his handbook on designing problem-solving learning environments, defines PBL as an instructional strategy characterized by: focusing on authentic, ill-structured problems; being student centered; allowing for self-directed learning by the students; and requiring regular self-reflection, where students monitor and adjust their learning. PBL has its foundations in situated learning, which is known for active learning, social mediation, meaningful learning, purposeful participation in communities of practice, and being situated in a specific context or learning culture. The following Teaching Meaningful Learning Model $^{9}$ (Figure 1) highlights the process characteristics and learning outcomes inherent in PBL.

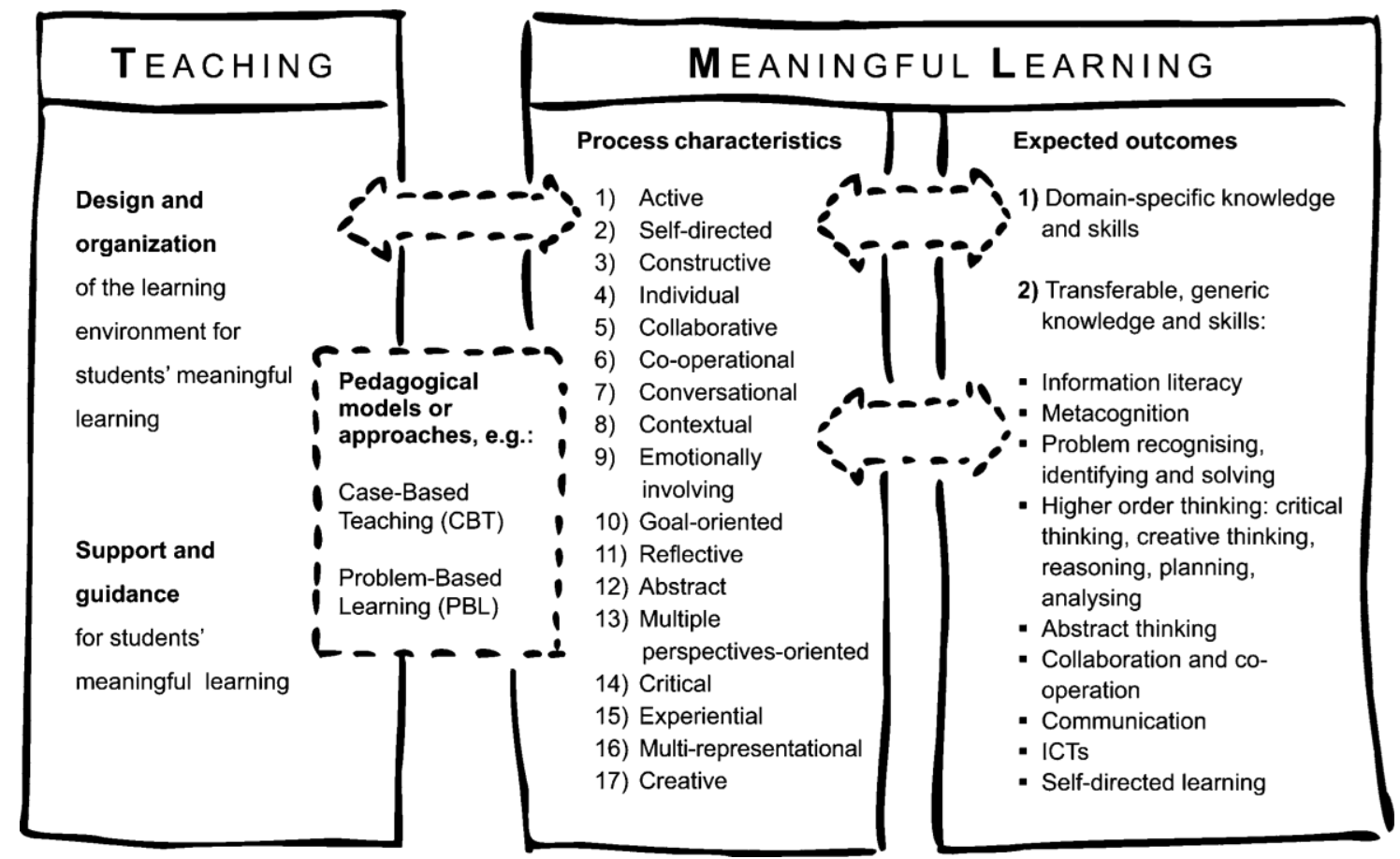

Fig. 1 Teaching Meaningful Learning (TML) Model for teaching and meaningful learnings $(\text { p. } 213)^{9}$

Barrett, Mac Labhrainn, \& Fallon ${ }^{10}$ provided an operational definition of problem-based learning that includes the following components: 1) students are presented with a problem; 2) students discuss the problem in a small group; 3) students engage in independent study drawing on outside resources; 4) students return to group, share information, peer teach, and work together on the problem; 5) students present and discuss their solutions; and students review and reflect, engaging in review of the process and each person's contribution.

It is important to clarify that problem-based learning and problem-solving are different. Problem-based learning centers on ill-structured, messy, problems that are authentic, or real-life 
in nature. These situations lack certain information integral to their resolution and often require an iterative approach to solving them that leads to new ideas, hypotheses, and learning.

One of the defining characteristics of the use of problems in problem-based learning is that students are deliberately presented with the problem at the start of the learning process. This is like getting the challenge of preparing a celebratory meal for a special occasion where no recipes or ingredients are given (pp. 56$57)^{10}$.

\section{Rationale for PBL in Engineering Education}

Jonassen, Strobel, and Lee ${ }^{5}$ conducted a study to gain a better understanding of the nature of problems faced in the engineering workplace. The study highlights some relevant aspects of these problems: (1) they are ill-structured; (2) ill-structured problems included aggregates of well-structured problems; (3) ill-structured problems have multiple, often conflicting goals; (4) ill-structured problems are solved in many different ways; (5) success is rarely measured by engineering standards; (6) most constraints are non-engineering; (7) problem solving knowledge is distributed among team members; (8) most problems require extensive collaboration; (9) engineers primarily rely on experiential knowledge; (10) engineering problems often encounter unanticipated problems; (11) engineers use multiple forms of problem representation; and (12) engineers recommend more communication skills in engineering curricula. These attributes of authentic engineering problems are important to keep in mind when designing your PBL environments. When designed correctly, employing an authentic "real-world" context will facilitate workplace transfer - "the ability to generalize solution methods from one problem to another, similar worked problem embedded in a different context" (p. 147) ${ }^{5}$. Not only will PLB hone students' problem-solving skills, but it will also help to develop the necessary professional skills set forth by ABET, such as teamwork, communication, and lifelong learning.

\section{Advantages/Disadvantages of PBL}

In his article on the PBL, Jones ${ }^{3}$ delineated clear advantages and disadvantages often associated with the implementation of PBL in medical curricula. Instructors considering adding PBL to their courses or labs should be mindful of these considerations. Advantages for using PBL include: 1) it makes the curriculum content relevant for students; 2) it focuses on learning core information in real scenarios; 3 ) it fosters transferrable skills needed for lifelong learning, including leadership, teamwork, communication, and problem-solving; 4) it nurtures selfdirected learning; 5) it increases motivation through the focus on authentic "real-life" situations; 6) it encourages deeper learning; and 7) it employs a constructionist approach, allowing learners to construct their own learning.

Along with these advantages, some disadvantages were also highlighted. With PBL, facilitators rather than lecturers lead the learning context. Because students are primarily learning from one another, they don't experience the "expert" knowledge of their professor, leaving them lacking in good "role models." Because students are in charge of his/her own learning, the 
knowledge acquired cannot necessarily be quantified or organized beforehand. Finally, PBL takes significantly more time than regular lecture-based courses, both in preparation and implementation.

\section{Research on PBL Implementation}

Problem-based learning is not a new educational trend. In fact it has been around for quite some time. It arose in response to educational initiatives in the $1960 \mathrm{~s}^{3}$. Howard Burrows first developed PBL and used it in medical education at McMaster University in Canada. From there it has spread throughout the world. PBL is now the standard for medical curricula worldwide 2,3,4. "And, whereas PBL may not form the foundation of every medical course within the western world, almost all courses include at least some component of PBL" (p. 485) ${ }^{3}$.

Although much research has been done on PBL in medical education, fewer studies have focused on PBL in engineering education. With all the literature that exists, even less is known about the trials and tribulations associated with the implementation of PBL in post-secondary contexts, including the factors impacting novice PBL adopters during this curricular change. When exploring research on implementation of PBL a handful of studies surface. These studies all hit on pieces of the larger puzzle, but fall short in providing any real comprehensive advice for first time PBL implementers.

Murray and Savin-Baden ${ }^{4}$ studied the effects of staff development on PBL. They explored the importance of staff development, which is key to preparing instructors to bridge the cultural divide from a lecture-based curriculum to a student-centered, active learning environment. The major piece of implementation advice gleaned from this study is the reminder to instructors to align instruction to assessment; something often overlooked when instructors adopt PBL into their courses. It is not enough to change the way students learn, but it is crucial that instructors also develop appropriate assessments aligned to this new approach.

Pecore and Haeussler-Bohan ${ }^{11}$ studied a PBL workshop experience focused on training teachers about PBL, and preparing them to become effective facilitators. They found that teaching experience, classroom management styles, familiarity with inquiry-based learning, and educational philosophies strongly impacted whether instructors thrived or struggled implementing a PBL lesson. This study speaks to the importance mindset and perspective can have on effective PBL implementation, making the shift to a new teaching style will be as much a mental effort as anything.

Tambouris et al. ${ }^{12}$ looked at the use of Web 2.0 technologies as part of PBL environments in hybrid courses (meeting both face-to-face and online). They found that students failed to fully maximize the resources available to them, and instead opted for greater face-to-face collaboration. This highlights another important struggle faced by instructors interested in implementing PBL into their courses - the impact of student perceptions. Students' perceptions of their learning environments and "how they learn" can have a significant impact on how effective the environment ends up being. 
Yadav, Subedi, Lundeberg, and Bunting ${ }^{13}$ explored the use of problem-based learning with electrical engineering students. While this study is one of the few studies to explore PBL implementation in engineering education, it explored the implementation process on a very shallow level, reporting that student perceptions were instrumental to the success/failure of the implementation.

Overall, while researchers agree that PBL can be an effective instructional strategy. It has been used effectively in medical school for over forty years. It is only more recently that engineering educators have been considering this approach. The benefits PBL demonstrates in terms of improving student learning and meeting ABET outcome standards has reignited a buzz around PBL. The question is not so much, "Should we?" but rather "How do we go about it?"

\section{Methodology}

\section{Research Design and Rationale}

This formative evaluation examines the development and implementation of a three-week PBL unit in a combined lecture and lab undergraduate environmental engineering course. All students participated in the PBL during their assigned weekly lab section. Researchers chose qualitative analysis to examine instructor and student experiences and to help answer the following research questions:

R1: What themes emerge from student and instructor interviews about their PBL experience?

R2: How can we use these themes to improve future PBL implementation?

Researchers interviewed 7 students ( 4 male, 3 female), 1 course instructor, and 2 graduate teaching assistants using open-ended, semi-structured interview formats. Researchers then recorded and transcribed each interview verbatim. Finally, researchers employed a grounded theory approach in analyzing the data. Through an open coding process, researchers categorized topics and discovered three emergent themes ${ }^{14}$.

\section{Participants and Context}

The PBL was implemented at a large, Midwestern university. The environmental engineering course instructor collaborated with graduate students in the College of Education to create the PBL environment that introduced the problem of choosing a biomass for the university's new biomass burner. All students participated in the PBL during their course lab sections during the three-week implementation period. Students worked on the PBL problem in previously established lab groups of four to five students. 


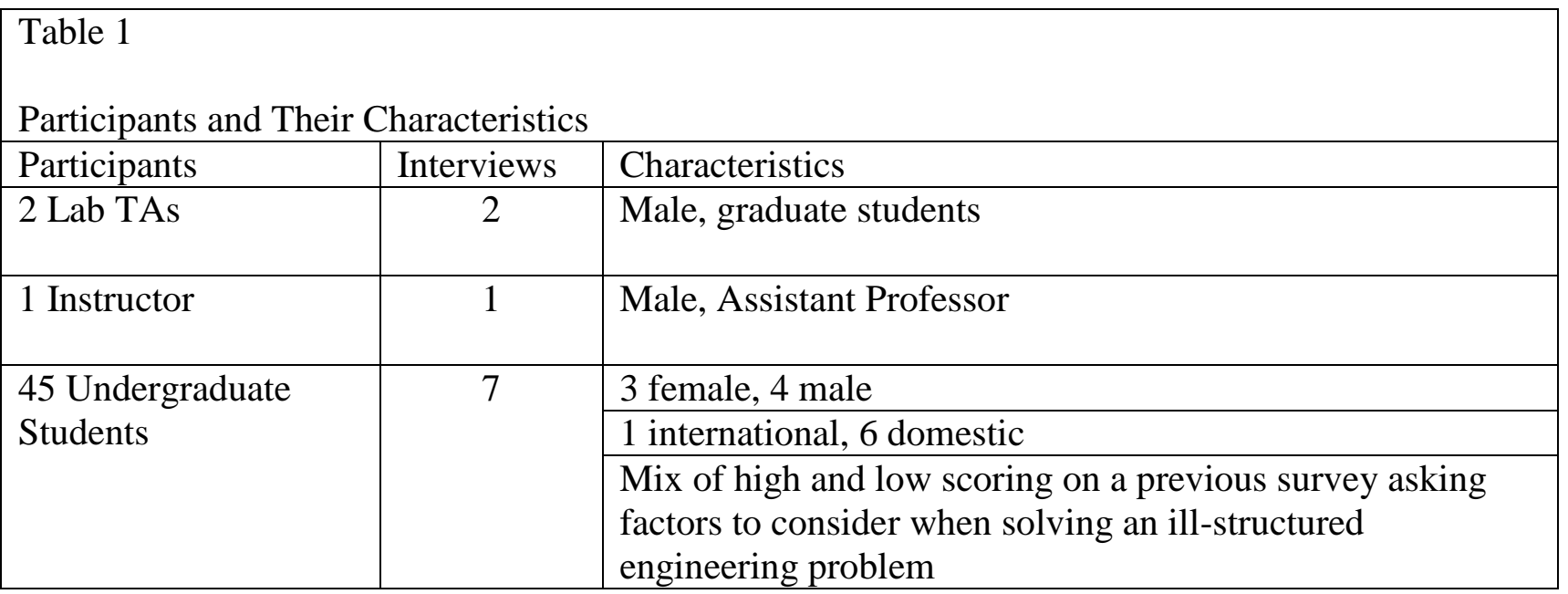

Two graduate teaching assistants (TAs) guided students through the PBL lab sessions that occurred during a three-week segment of the 16-week course; they were responsible for ensuring that students were clear on how to navigate through the website and for providing the scope and sequence of assignments each week. Two weeks after the groups turned in their final lab papers, students toured the university power plant. The instructor introduced the PBL in lecture but was not present during lab sessions.

\section{Procedures}

The researchers obtained IRB approval prior to commencing research. The course instructor offered extra credit to students who chose to participate in pre and post PBL questionnaires and individual interviews. For those students not interested in participating in the research study or not selected to give an interview, researchers provided alternative avenues for extra credit. Researchers chose students interview participants based on gender, nationality and their response to a survey questions, in which they were asked to list factors to consider when working on an open-ended engineering problem. Researchers recruited interview participants via email. Participants reflected a representative sample of the overall course demographics.

Researchers recorded interviews in quiet rooms in the engineering library. Student interviews occurred approximately eight weeks after completion of the PBL implementation while instructor interviews occurred approximately nine months later. Subjects provided signed consent forms. Researchers audio recorded the interviews and stored the recordings in a password protected zip file.

\section{Data Analysis and Results}

The researchers analyzed the interview transcripts independently. Each researcher used open coding to note emerging ideas. Then each researcher grouped their themes into concepts. After reaching consent on themes, the researchers integrated their concepts into a master list. Researchers noted three major emergent themes: student implications, instructor implications and PBL considerations. 


\begin{tabular}{|c|c|c|}
\hline \multicolumn{3}{|c|}{\begin{tabular}{|l|} 
Table 2 \\
Concepts Resulting from Grounded Theory Analysis
\end{tabular}} \\
\hline STUDENT & INSTRUCTOR & PBL \\
\hline \begin{tabular}{|l|} 
Self-Directed Learning \\
\end{tabular} & Guided Learning & Logistical Considerations \\
\hline Information Seeking & Justifying Decisions & $\begin{array}{l}\text { Exposure to Engineering } \\
\text { Scenarios }\end{array}$ \\
\hline Effort & Group Work Pros and Cons & Emotional State \\
\hline Engagement & PBL Development & \\
\hline \begin{tabular}{|l|} 
Desire for Hands-On \\
Learning
\end{tabular} & & \\
\hline
\end{tabular}

\section{Analysis}

\section{Student Implications}

Consistent with previous PBL findings ${ }^{6,9}$, the category of self-direction emerged from student interviews. Student 7 noted, "I think it (the PBL) definitely made us have to be more independent about it because we weren't being, you know, being told exactly what we needed to do." Although the PBL environment was designed to guide students through a series of tutorials and deliverables, it did not provide detailed steps that students needed to complete. The change to self-direction required group orienting. The most difficult aspect of the PBL, according to Student 2, was "trying to figure out a process because one wasn't laid out. So, trying to figure out where you're starting, where you're ending, and basically how to get from A to B."

Those learners who have a problem getting from point A to point B may seek additional help. Authors categorized this as information seeking and found that students sought additional help through TAs and group members. "If it came right down to it if I did have questions I could just ask (the TA), then the other member of the group and say, 'do you know what's going on?' I think having the people there was helpful." Instructors should encourage student collaboration and may need to provide some guidance to PBL learners.

Another emerging student concept was effort. Student 6 discussed the payoff for the effort required to solve equations by hand. "It helps me understand more. Like the whole calculation process. Cause if you just put the equation in Excel it's just a click and you don't know what's going on." However, Student 5 only tied effort to grading. "If things are weighted more, I will definitely put more effort into them." To ensure student effort, instructors should grade PBLs and place more weight on tasks where they expect students to put the most effort. If group participation is expected, grades should include a measure of each individual's contribution to the group. 
Authors found that lack of engagement may hinder PBL performance. The websitebased PBL was typically accessed by groups of 4-5 using a single laptop. Student 7 reflected that, "not everyone had their laptops and it was kind of difficult to, you know, all sit around the same screen if you didn't have yours." Student 5 also voiced a complaint about having to stay engaged due to screen sharing. "Whoever was engaged wouldn't have had to turn around and catch the people up that weren't engaged at the time. I think everyone would have been a lot more focused." To prevent screen sharing bottlenecks, instructors should either encourage all students to bring a laptop or tablet to class or reserve a computer lab for the class.

The final student category is the lack of hands-on learning. The PBL included research, analysis and evaluation using website information and problem solving. No experiments were performed as part of the PBL. Student 1's biggest complaint about the PBL was that "it's not hands on." Student 1 suggested adding a lab that would allow students to discover qualities of different types of biomass. "Instead of learning about the biomass on here, we could have actually tested the different types and stuff and looked at it through that different way." Student 3 also echoed this sentiment and suggested combining the PBL with a lab test that "get[s] your hands dirty doing it." This is consistent with the Jones' constructivist approach ${ }^{3}$. Students actually asked for tasks that would require additional effort if it meant they could discover or construct biomass information.

\section{Instructor Implications}

The role of both the PBL environment and the instructor in guiding student learning was a category that emerged both from student and instructor interviews. Student 2 described PBL guidance as "something that kind of pushes you in the right direction, but then you still have the freedom to pick." Teaching Assistant 2 described some of the benefits of the role as a guide. "I don't really have to prepare much because it's all there. And also secondly, it (the PBL) keeps everything in order. I feel it's logical." As previously mentioned, a PBL unit will require a shift to student-centered learning. In order for this to occur, the instructor must move away from the traditional instructor-led approach.

Another category that instructors emphasized was justifying decisions. TA2 felt that the PBL's greatest benefit was to make students take a different approach to problems that allowed them to solve "based on real life" rather than on solving equations. However, this approach was new and students were concerned about whether their biomass fuel choice was correct. TA1 recalled, "I tried to tell them that there wasn't necessarily a right answer, as long as you were properly backing it up. I think that's kind of what engineering is really." The course instructor also echoed this sentiment. "I could care less what decision they made. It was whether or not they could defend that decision."

Decision-making and justification can be greatly enhanced by working in groups, a category mentioned by students, the TAs, and the course instructor. Students discussed the pros and cons of working in groups. Student 7 described group work as beneficial because "you can bounce ideas off each other" and "brainstorm what you need to do." Student 2 felt that working in a group offered a kind of "double check mechanism, so we weren't all just making different 
mistakes." These experiences are consistent with the notion of problem solving distributed ${ }^{5}$ among team members. However, Student 5 noted their lab group of 5 students had to take turns looking at the computer screen while others sat behind doing nothing. "I know whoever wasn't engaged at the time was always, c'mon, hurry up, let's get done, move on!'” Instructors should consider decreasing group size from 5 to 3 in order to keep all group members engaged.

The authors categorized PBL development as having instructor implications. Developing a PBL unit and website can take a lot of planning. The course instructor pointed to the value of suggested getting help from experienced PBL developers. "I think to get into this you really need to not only have a concept of what you want to do but then get help from someone who's built these sort of websites before. I think there's just too much of a learning curve for a faculty member to do it on their own." The instructor was surprised at the amount of time it took to develop the PBL. He recommended coming up with a PBL development procedure to assist with more rapid creation of new PBLs.

\section{PBL Implications}

When implementing a PBL as part of a lab, logistics are very important. TA1 recommended, "I think you have to start at the beginning and go through it yourself and figure out how much time to dedicate to each subsection." This means working through all the material in each section of the PBL and allocating lab time accordingly. In addition, instructors should pad extra time in case of unexpected schedule changes. For example, during the air quality PBL unit, the university cancelled classes for several days due to a major snowstorm.

In addition to logistics, PBL planning should include exposing students to real-life scenarios rather than just learning about solving equations or learning about theories. Several students mentioned this immersion into real world learning. Student 1 noted, "I'd have to say... it was kind of cool how we had little videos, like you were chosen to do this and it's just kind of trying to solve it. It felt a little more real than just doing a worksheet..." Student 3 thought it was nice to "actually do something that isn't just a theory problem." The course instructor kept the real-world environmental engineer experience in mind when he helped design the PBL unit. He reflected, "I would like to believe that the students walked away from the class with a better sense of how the role of the environmental engineer, what role an environmental engineer played in that context."

One final experience that PBL implementers are likely to run across is student emotion while working on a PBL. Students used to instructor-led discussions must adjust to group work, student-centered learning, solving ill-structured problems, and justifying decisions. The course instructor noted that, "One of the more important lessons that they learned was the whole idea of there is not right answer. And I know that there're a number of students who are very uncomfortable with that, particularly engineering students." Student 6 joked that, "from my perspective the whole process is torturing (laughs)... But that's a good sign... if you feel torturing that means that you really learning, you're really learning these things." Instructors 
should reassure PBL student that is normal to experience frustration or discomfort when first starting a PBL.

\section{Conclusions:}

\section{Future considerations}

The following considerations stem from lessons learned from this PBL implementation and include a list of pitfalls to avoid when planning your future PBL units. The advice provided corresponds with designing a course, teaching a course, and working with students.

\section{Designing a course}

When designing a course, it is important to find partners to assist you in this process. Getting started in PBL can be a daunting task. This shift to a constructivist learning environment requires more upfront planning than does the average lecture-based course. If you are new to PBL design, consider finding someone in your department who has more experience to help orient you to the process. Otherwise, consider seeking assistance from the instructional support teams offered at your institution or find researchers on your campus who may be involved in PBL research.

Timing is important to the success of any PBL experience. It is important to start developing early. Your environments may need at least a semester of planning before they are ready to be implemented. Making an effort to streamline the design process can be beneficial as you seek to add PBL opportunities throughout your course or across the curriculum. Templates can be an effective way of helping you do this. Because you are not employing the traditional method of providing information upfront and then having students solve problems related to what you teach, it is critical that any PBL environment you design provide ample scaffolding. Consider providing worked examples of similar situations. Find ways to guide students throughout the process, that both allow them to be responsible for their own learning, but don't leave them lacking crucial support through this new process.

When training your TAs it is important to ensure they have access to: 1) a unit overview - including suggested lesson plans per lab period with timing suggestions for each section of the problem; 2) a list of supplemental resources - the TAs need to be better prepared for the materials than what the students might actually need; 3) worked examples - showing exactly how to do any calculations that will be required in the PBL environment; and 4) a site map (a hierarchical list of website content and structure) - clearly delineating where everything is located and what the corresponding purposes are.

\section{Teaching a course}

When teaching a course there are a number of logistical considerations of which to be concerned. For instance, when planning a site visit or tour as part of your PBL experience, 
considering creating a picture walkthrough or guide that is site specific. This can serve as a great introduction to the unit or advanced organizer for students. Additionally, this information proves especially helpful for international students who may be struggling with new vocabulary or TAs who need a little refresher before going on a visit. Ensure that contingencies are in place for when the implementation actually occurs. Pesky snow days can put a crimp in your plans. And if you are only using PBL for part of your semester, it is important to have enough time dedicated to it, in order to maximize student learning. If your PBL is going to require technology access that is not a normal part of the class or lab, ensure that you schedule computer lab time early, (a semester ahead if possible). Not having proper access to necessary technology really impacts student engagement.

As a seasoned veteran in your field, it is often easy for you to see connections between the lab and lecture. Students often lack this sophistication. This skill is even more important when you are implementing PBL into a lab. If you are not present at all in labs, ensure that your TAs are aware of ways to reinforce the connections that are being built between lab and lecture. For example, "In class, you are discussing...we are doing something quite similar here with..." Don't forget to align your assessment with your new curriculum. Don't put all the time into planning a new approach and then keep your same exams. It will be important to make sure assessments properly align with the new instruction. Your new instructional collaborator should be able to help you with this.

\section{Working with students}

When working with students, there are a few things that are good to consider. Engineering students tend to be very grade oriented. As a result they will determine how much effort to expend based on the amount of credit they will receive. Consequently, there needs to be a correlation between where you expect student effort and what is graded. If you want work to be taken seriously, then you must grade it. You will need to incorporate a mechanism to ensure that all students are participating regularly in the learning environment. Individual reflections or independent ratings of group effort are easy ways to increase individual accountability and ensure that all students are participating and learning throughout each phase of the PBL.

Remember PBL may be as new to your students as it is to you. It will likely not be a part of their schema for learning; so let them know up front that feeling a little uncomfortable with this new approach is normal. Keep in mind that group size impacts student engagement, Groups that are too large may end up with students on the periphery, doing little other than watching their peers learn. Groups that are too small may leave the members feeling overwhelmed with the scope of the project. The ideal group size is 3; any more and you risk a significant drop in engagement. Individual reflections, while increasing individual engagement are also a key component of any successful PBL experience. 


\begin{tabular}{|c|c|}
\hline \multicolumn{2}{|c|}{ When designing a course } \\
\hline Criteria & Advice \\
\hline Find Partners & $\begin{array}{l}\text { Find someone in your department who has more experience to } \\
\text { help orient you to the process } \\
\text { Seek assistance from the instructional support teams } \\
\text { Find researchers on your campus }\end{array}$ \\
\hline Make Time & $\begin{array}{l}\text { Start developing early } \\
\text { You may need at least a semester of planning before } \\
\text { implementation }\end{array}$ \\
\hline Use a Template & $\begin{array}{l}\text { Streamline the design process } \\
\text { Templates can be an helpful }\end{array}$ \\
\hline Include scaffolding & $\begin{array}{l}\text { Provide ample scaffolding. } \\
\text { Consider providing worked examples of similar situations. }\end{array}$ \\
\hline Training for TAs & $\begin{array}{l}\text { Unit overview with lesson plans and suggested timing } \\
\text { Supplemental resources } \\
\text { Worked examples } \\
\text { Site map }\end{array}$ \\
\hline \multicolumn{2}{|c|}{ When teaching a course } \\
\hline Criteria & Advice \\
\hline Site visits/tours & Picture walkthrough/guide that is site specific \\
\hline Logistics & $\begin{array}{l}\text { Contingency plan for bad weather } \\
\text { Schedule computer lab time early, (a semester ahead if possible) }\end{array}$ \\
\hline Building connections & $\begin{array}{l}\text { Reinforce connections between lab and lecture } \\
\text { Align your assessment with your new curriculum }\end{array}$ \\
\hline \multicolumn{2}{|c|}{ When working with Students } \\
\hline Criteria & Advice \\
\hline Accountability & $\begin{array}{l}\text { If you want work to be taken seriously, then you must grade it } \\
\text { Individual reflections or independent ratings of group effort }\end{array}$ \\
\hline Emotional State & $\begin{array}{l}\text { Remind students that feeling a little uncomfortable with this new } \\
\text { approach is normal }\end{array}$ \\
\hline Engagement & $\begin{array}{l}\text { Group size impacts student engagement } \\
\text { The ideal group size is } 3 \\
\text { Individual reflections }\end{array}$ \\
\hline
\end{tabular}


In this paper, we presented the results of a qualitative case study in which a PBL environment was implemented into a PBL lab unit in a traditional environmental engineering lecture with lab course. 10 participants ( 7 students, 1 course instructor, and 2 graduate teaching assistants) were interviewed during the process. Using grounded theory, three themes emerged: student implications, instructor implications, PBL considerations. The data collected and the corresponding emergent themes provide rich advice for educators considering PBL implementation in future courses.

\section{Bibliography}

1. Direito, I., Pereira, A. \& Duarte, A. M. d. O. (2012). Engineering undergraduates' perceptions of soft skills: Relations with self-efficacy and learning styles. Procedia - Social and Behavioral Sciences, 55(0), 843-851.

2. Bouhuijs, P. A. (2011). Implementing problem-based learning: Why is it so hard? REDU. Revista de Docencia Universitaria, 9(1), 17.

3. Jones, R. W. (2006). Problem-based learning: description, advantages, disadvantages, scenarios, and facilitation. Anaesthesia and Intensive Care, 34(4), 485-488.

4. Murray, I. \& Savin-Baden, M. (2000). Staff development in problem-based learning. Teaching in Higher Education, 5(1), 107-126.

5. Jonassen, D., Strobel, J., \& Lee, C. B. (2006). Everyday problem solving in engineering: Lessons for engineering educators, Journal of Engineering Education, 95(2), 139-151.

6. Jonassen, D. H. (2010). Learning to solve problems: A handbook for designing problem-solving learning environments. New York, NY: Routledge.

7. Hakkarainen, P. (2009). Designing and implementing a PBL course on educational digital video production: lessons learned from a design-based research. Educational Technology Research and Development, 57(2), 211228.

8. Barrett, T., Mac Labhrainn, I., \& Fallon, H. (2005). What is problem-based learning. Emerging Issues in the Practice of University Teaching and Learning, 55-66.

9. Pecore, J. L., \& Haeussler-Bohan, C. (2012). Problem-based learning: Teachers who flourish and flounder. Curriculum and Teaching Dialogue, 14(1 \& 2), 125-138.

10. Tambouris, E., Panopoulou, E., Tarabanis, K. Ryberg, T., Buss, L., Peristeras, B., Lee, D., \& Porwol, L. (2012). Enabling problem based learning through web 2.0 technologies: PBL 2.0. Educational Technology \& Society, 15(4), 238-251.

11. Yadav, A., Subedi, D., Lundeberg, M. A., \& Bunting, C. F. (2011). Problem-based learning: Influence on students' learning in an electrical engineering course. Journal of Engineering Education, 100(2), 253-280.

12. Corbin, J. and Strauss, A. (2007). Basics of qualitative research: Techniques and procedures for developing grounded theory. Thousand Oaks, CA: Sage Publications. 